\title{
FLOWERED-GEODBAPP: AN APPLICATION BASED ON CROWD-GENERATING DATA USING SENTINEL2 IMAGERY
}

\author{
M. T. Melis ${ }^{\text {a* }}$, F. Dessì a ${ }^{\text {, P. Loddo }}{ }^{\text {b }}$, C. La Mantia ${ }^{\text {b }}$, S. Da Pelo ${ }^{\text {a }}$, A.M. Deflorio ${ }^{\text {b }}$, G. Ghiglieri ${ }^{\text {a }}$, \\ B.T. Hailu ${ }^{c}$, K. Kalegele ${ }^{\text {d }}$, B. N. Mwasi ${ }^{\text {e }}$ \\ ${ }^{a}$ TeleGIS Laboratory, Dept. of Chemical and Geological Sciences, University of Cagliari, via Trentino 51, 09127 Cagliari, Italy \\ titimelis@unica.it \\ ${ }^{\mathrm{b}}$ Planetek Italia SRL, via Massaua, 1270132 Bari, Italy- lamantia@planetek.it \\ ${ }^{\mathrm{c}}$ School of Earth Sciences, University of Addis Ababa, College of Natural Sciences, P.O. Box 1176 Addis Ababa, Ethiopia - \\ binyam.tesfaw@aau.edu.et \\ ${ }^{\mathrm{d}}$ Nelson Mandela African Istitution of Science and Technology, P.O. Box 447, Tangeru Campus, Arusha, Tanzania - \\ kalegs03@gmail.com \\ ${ }^{\text {e }}$ School of Environmental Studies, University of Eldoret P.O Box 1125 - 30100, Eldoret, Kenya - benmwasi@gmail.com \\ * Corresponding author
}

Commission III, WG III/1

KEY WORDS: Land cover, ESA Sentinel, Crowd-generating data, Rift Valley, Fluoride

\begin{abstract}
:
This study is part of the EU H2020 research Project FLOWERED (de-FLuoridation technologies for imprOving quality of WatEr and agRo-animal products along the East African Rift Valley in the context of aDaptation to climate change). FLOWERED project aims to develop technologies and methodologies at cross-boundary catchment scales to manage the risks associated with high Fluoride water supply in Africa, focusing on three representative test areas along the African Rift Valley (i.e. Ethiopia, Kenya and Tanzania), characterized by high fluoride contents in waters and soils, water scarcity, overexploitation of groundwater and high vulnerability to risks arising from climate change, as drought and desertification. It also is empowering local communities to take responsibility for the integrated-sustainability of the natural resources, growing national and international environmental priorities, enhancing transboundary cooperation and promoting local ownership based on a scientific and technological approach.

Within the FLOWERED project, the transition from the land cover to the land use and water use maps is provided through the development of a mobile application (FLOWERED-GeoDBapp ). It is dedicated to the collection of local geo-information on land use, water uses, irrigation systems, household features, use of drinking water and the other information needful for the specific knowledge of water supply involving local communities through participative approach. This system is structured to be populated, through an action of crowd-generating data by local communities (students and people involved mainly by NGOs). The SHAREGEODBapp is proposed as an innovative tool for water management and agriculture institutions at regional and local level.
\end{abstract}

\section{INTRODUCTION}

\subsection{Volunteered Geographic Information}

GIS changed the perception of geographical representation although at the same time has led to a number of debates regarding its use (Fitzjohn, 2007). The shift from mapping to map analysis marks a turning point in the collection and processing of geographic data. The elements of a basic map (i.e. points, lines and area) provide "spatially-aggregated" descriptions. Modern GIS-based cartographic analysis enables a transition towards mapping surfaces and quantitative treatment of data. This changes our perspective about the relationships of mapped objects and challenges the established conceptual differences between spatial and non-spatial data.. In traditional cartography, maps are static, compared to GIS-based cartography. In a GIS, the dynamic link between of the spatial data (i.e. lines, points and areas) and the database enables the user to produce as many maps as the attributes supported by the database (Vogiatzakis et al., 2015).

A new source of geographic information was identified by Goodchild in his studies: he proposed the term "Voluntereed Geographic Invformation (VGI)" as a special case of the more general Web phenomenon of user-generated content (Goodchild, 2007). VGI has been considered closely related to the concept of crowdsourcing (Howe, 2008). Indeed, it can be recognise that information obtained from a crowd of many observers is likely to be closer to the truth than information obtained from one observer (Goodchild et al.,, 2010).

Moreover, an interesting tool of geo-data collection can be considered the "citizen science". It can be defined, among other features, the set of scientific activities in which non professional scientists voluntarily participate in data collection (Silvertown, 2009).

Many initiatives are promoting in the last years new technologies and inputs from geodata to assure the sharing of information (GODA -Global Open Data for Agriculture and Nutrition, 2017).

The increasing role of VGI and Digital Earth, as images captured from satellites, has been recognised as a tool of rapid response to disaster and for human health (Goodchild et al.,, 2010).

Moreover, a large interest to these methodologies,, and specifically on the use of crowdsourced geographic information, is demonstrated by the investments of economic organization, i.e. the World Bank Global Facility for Disaster Reduction and Recovery (GFDRR), that is carrying out a research on the use of 
crowdsourced geographic information in government (https://crowdgov.wordpress.com).

While these activities receive a large consensus in the web communities and many VGI projects such as OpenStreetMap (OSM) involve a great number of people, researchers continue questioning the reliability and fitness for use of crowdsourced data (Arsanjani et al. 2013; Basiri et al. 2016; Senaratne et al., 2017,)

In this study we analyse the possibility to apply an action of crowd- generating data to improve the contents of land cover maps collecting information on water use in three areas of Africa affected by fluoride contamination. Fluoride is one of the most severe natural contaminants is. It was estimated (Fawell et al., 2006) that more than 260 million people worldwide consume drinking water with a fluoride content $>1.0 \mathrm{mg} / \mathrm{L}$. The World Health Organization Guideline threshold for fluoride in drinking water is $1.5 \mathrm{mg} / \mathrm{L}$ (WHO 2011). High fluoride concentrations in groundwater, up to more than $30 \mathrm{mg} / \mathrm{L}$, widely, occur in the United States of America, Africa and Asia (Mohapatra, 2009, and references therein) so that the security of drinking water supply was considered one of the goals of the Millennium Development Goals (MDGs) and among the Sustainable Development Goals (SDGs n. 6= Ensure availability and sustainable management of water and sanitation for all). Fluoride contamination may also affect rivers and soils thus extending to agriculture and resulting in a relevant issue for food security and also for ecosystems.

\subsection{FLOWERED Project}

This study is part of the EU H2020 research Project FLOWERED (de-FLuoridation technologies for imprOving quality of WatEr and agRo-animal products along the East African Rift Valley in the context of aDaptation to climate change). FLOWERED project aims to develop technologies and methodologies at cross-boundary catchment scales to manage the risks associated with high Fluoride water supply in Africa (figure 1). This study has been developed at regional scale along the East Africa Rift to reconstruct the general geological, hydrogeological and geochemical conditions associated to the presence of fluoride in the water. Three study cases in Ethiopia,
Kenya and Tanzania have been chosen to analyse the local relationships between contaminated water and water supplies to propose mitigation actions to the local communities (figure 2). Innovative technologies and low cost systems for water defluoridation will be proposed taking into account the complexity of issues linked to water in developing countries (operational and effective applications). The approach proposed in FLOWERED is based on a detailed knowledge of the hydrogeological setting, with the identification and mapping of the specific geological conditions of water contamination and its relation with the different land uses (Da Pelo et al., 2017). These data will constitute the necessary information for the implementation of a sustainable water management, and for the proposal of sustainable and suitable strategies for water sanitation and agricultural system.

The proposed methodology is organised into laboratory and field scale research activities based on the integration of research and innovative activities, included with a deep analysis of the local environment conditions that drive the final technological solutions and the proposal of good practices, through a participative approach.

In the framework of the project, the development of a land cover mapping system is a primary key for the understanding and to assess the fluoride pollution. A land cover mapping system has be defined with a focus on the ground effects caused by pollution due to the high concentration of Fluoride in water.

Data from the Copernicus Programme and in particular images from the Sentinel satellites together with other free and open access medium resolution satellite imagery will be used to detect the geological features of the surfaces through visual inspection and band ratios on multispectral data. The comparison of multitemporal images, showing the environmental changes in the past years, will allow the identification of active geomorphological processes.

This study aims to transform, through collection of geolocalised data, the land cover maps based on multispectral images into dynamic land use maps. Moreover, each land use class (polygon in the map) will be correlated to specific water uses, defined in a dedicated legend.

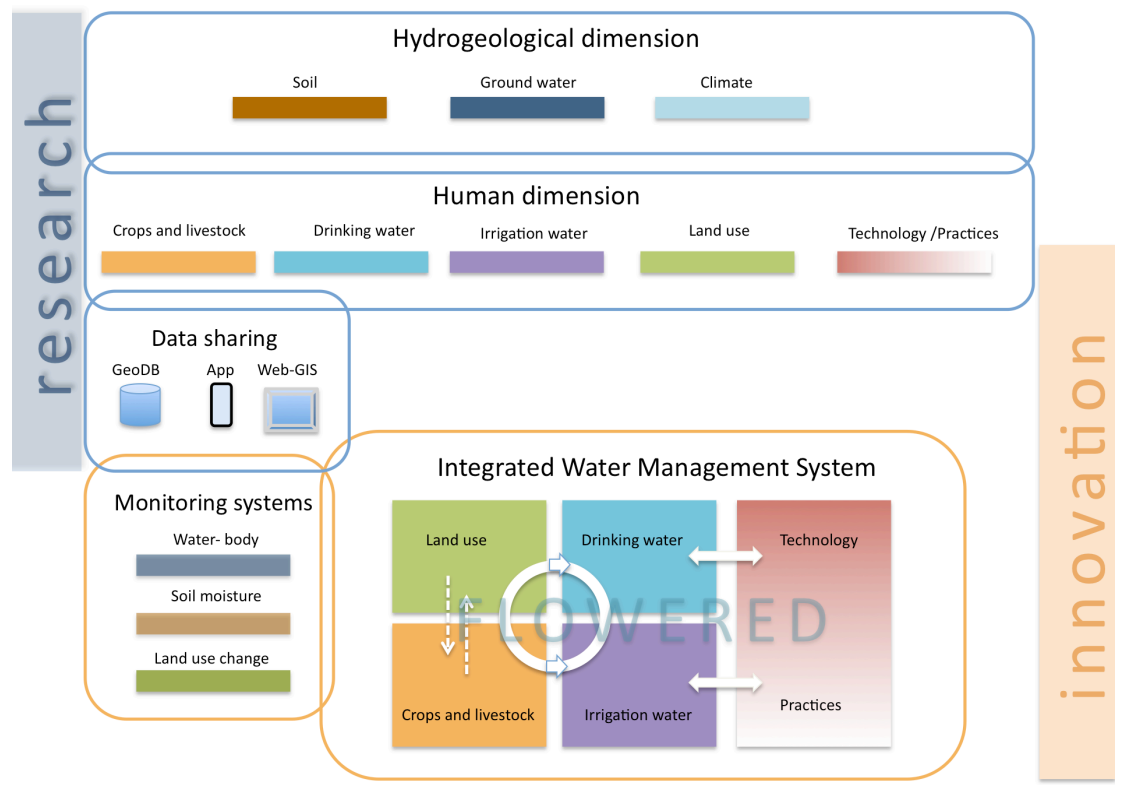

Figure 1. FLOWERED methodology is planned to answer to the need to achieve an Integrated Water Management System based on the deep knowledge of the natural and human dimension of the study areas. 


\section{STUDY AREA AND DATA SET}

\subsection{Study area}

The study area is located in the East African Rift System (EARS). In this area, the highest groundwater fluoride contents in the world have been recorded as a consequence of normal water-rock interaction at low-moderate temperatures involving volcanic rocks and associated deposits (calcareous tufa, lahar and ashes). Concentrations of up to $20 \mathrm{mg} / \mathrm{L}$ in Ethiopia (Wonji/Shoa area), and even more than $100 \mathrm{mg} / \mathrm{L}$ in Tanzania (Gaciri and Davies 1993; Ghiglieri er al. 2010, 2012; Gizaw 1996), and in Kenya (Walvekar and Qureshi 1982; Wambu and Muthakia 2011) have been measured.

In the EARS about $90 \%$ of the population exhibit varying degrees of fluorosis symptoms corresponding to over 80 million people (Smedley et al., 2002).

The EARS, being an active continental rift, is characterized by widespread volcanism and tectonic extension. The regional fault pattern and the volcanism are strongly associated also to rifting maturity stages. Early stages of rifting infer widely-spaced faults, volcanism and hydrothermal fluids ascent localised on the rift border, while mature stages express closely-spaced fault pattern, diffuse volcanism and hydrothermal fluids ascent in the rift floor. An intermediate stage between these two endmembers implies an incipient internal faulting. The orientation of faults strongly influences the recharge area, the geometry and relationship between aquifers and groundwater flow direction.

The hydrogeochemical evidence indicated that fluoride concentration in EARS aquifers reaches up to $70 \mathrm{mg} / \mathrm{L}$ and is related to different factors. These include temperature, $\mathrm{pH}$, solubility of fluorine-bearing minerals, anion exchange between hydroxyl and fluoride ions, water residence time. Water rocks interaction, exacerbated by heat anomaly generated along regional faults or from recent hot eruption centres, favor high fluoride incorporation into groundwater. Safe fluoride groundwater also occurs, mainly related to basaltic or phonolitic unaltered lava-flow fractured or autobrecciated (Ghiglieri et al., 2017).

The study area in Ethiopia is into the Ethiopian Rift Valley. Here the rift extends from Afar triangle (North East) to lake Turkana (South West). The rift valley of Ethiopia divided in to Afar Triangle and Main Ethiopian Rift (MER). The former has lowest elevation including Denakil Depression (Dallol), which is about $130 \mathrm{~m}$ below sea level and MER exhibits the presence of 9 major lakes in Ethiopia.

The study site in Kenya covers the catchment basins of Nakuru and Naiwassa lakes in the Nakuru County. The landscape is characterised by the presence of these lakes in the low land and volcanic edifices connected to the rifting activity. The area has a high concentration of inhabitants and agriculture is extensive and constitutes an important economic resource.

Tanzania, neighbouring Kenya on the north and Indian Ocean on the east, is considered by the WHO to have communities, and respective livelihood, that are at high risk of being affected by fluoride-contaminated water (Fawell et al., 2006). These include the communities living along volcanic areas of the rift valley in the northern parts of the country around mountains Kilimanjaro and Meru. Most of these are rural communities which access drinking water primarily from streams that run down mountain slopes, natural springs and groundwater. The main economic activities in two basins of Pangani and lake Eyasi, our study areas, are small-scale farming, irrigated agriculture, fishing, tourism, mining, and industry. In recent years, literacy level within these communities have increased while the national-wide mobile phone penetration was $80 \%$ by December 2016. (https://www.tcra.go.tz/images/documents/telecommunication/ CommStatDec16.pdf.

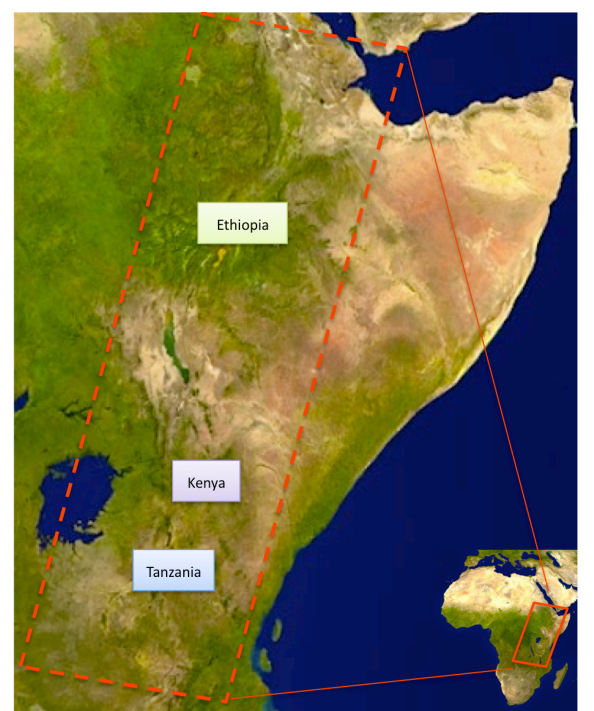

Figure 2. Sketch map of the study area and localization of the three study cases.

\subsection{Sentinel data}

Open satellite data from Sentinel 1 and Sentinel 2 missions have been considered in FLOWERED as input base data for the implementation of automatic algorithms able to produce land cover maps on the 3 test sites. Sentinel satellite missions are being developed by the European Space Agency (ESA) within the Copernicus Space Component, part of the Copernicus programme headed by the European Commission (EC) in partnership with ESA.The Sentinels already in orbit are providing massive amounts of data that are made freely available by Copernicus for operational monitoring and scientific exploitation.

The proposed land cover legend has been based on the ESA Climate Change Initiative (CCI) Land Cover nomenclature and is built on the United Nations (UN) Food and Agriculture Organization (FAO) Land Cover Classification System (LCCS). The LCCS was designed as a hierarchical classification, which allows adjusting the thematic detail of the legend to the amount of information available to describe each land cover class, whilst following a standardized classification approach. If further and more accurate local information on site specific land cover classes will be available during the project life then a greater detail will be added to the proposed legend.

Sentinel time series will also be investigated in order to analyze potential correlation between fluoride water concentration and the vegetation status (water stress, alterations of the phenological cycle of the crop, etc.).

\section{METHODOLOGY}

\subsection{Land cover prototype workflow design (Planetek)}

Sentinel-1 and 2 multitemporal images are classified by implementing supervised algorithms trained with information extracted from ancillary data or carried out from a photointerpreter.

The production workflow is based upon the state-of-art established in previous projects like GlobCover and ESA Climate Change Initiative with further exploitation of the potential of Sentinel-1 SAR images for temporal gap-filling of the optical image time series. 
The processing chain can be divided into five major processing steps as schematically shown in the following Figure 3:

I. Sentinel dense time series data selection: the multitemporal dataset of Sentinel-1 and 2 offers high resolution information (up to $10 \mathrm{~m}$ ) with very high temporal frequency (up to 5 days). The S2 selection is guided by cloud coverage percentages, complemented by $\mathrm{S} 1$ time series when optical data suffers from high cloud cover percentage.

II. Pre-processing: atmospheric correction and cloud masking is applied to the optical images while the application of speckle filtering to $\mathrm{S} 1$ data needs further evaluation in relation to potential improvements of the final classification's accuracy. III. Intermediate products: the extraction of a set of intermediate products is performed to support the classification process: several multi-temporal spectral (NDVI, NDWI, Brightness index) indices are calculated together with multitemporal metrics.

IV. Ancillary data integration: the available ancillary data over the test areas are integrated into the process in order to train the classifier. For the Arusha test case prototype, only the Open Street Map layers have been used. The integration of other existent land cover maps has not been feasible as their scale is not compatible with the high resolution of the desired product (e.g. GlobCover 2009 has 500m res., ESA CCI LC has 300m res.).

V. Classification model implementation: preliminary results have been obtained by implementing supervised and unsupervised pixel-based and object-based classification algorithms applied to the pre-processed images and intermediate products.

VI. Finalization of the land cover map: finally, a refinement of the extracted maps is foreseen in order to improve the final quality or to further detail the land cover classes when further ancillary information (e.g. specific features extracted from OSM) are made available.

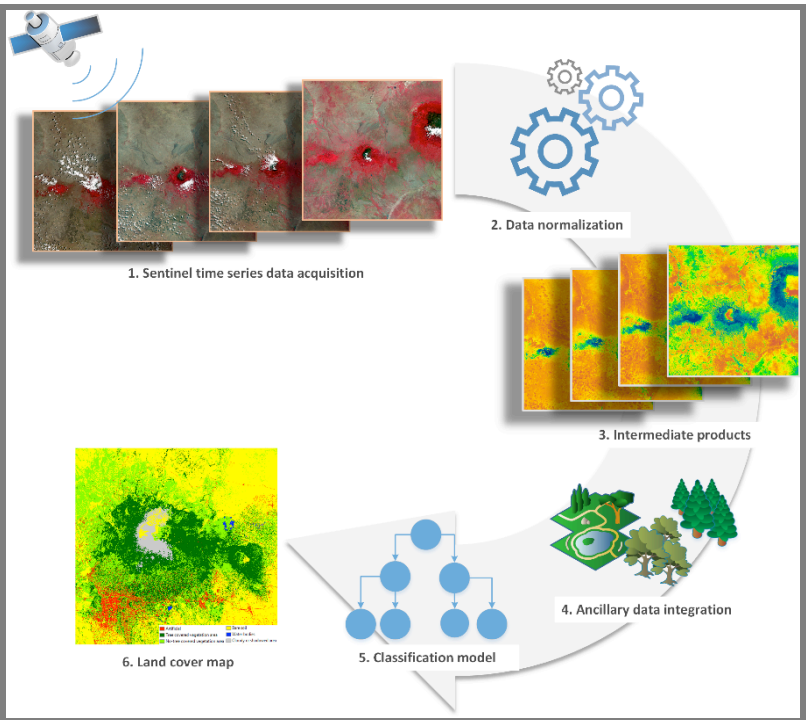

Figure 3: Schematic illustration of the production workflow of the land cover map

\subsection{Land cover map update}

The main goal of FLOWERED GeoDBapp is to support the process of land cover mapping and to collect data on land and water uses. Furthermore, the research started from the need to update the land cover classification to use it as the land use map for water management. Changes in land use in the study areas are very quick as they are linked to local climate conditions.
Moreover, as in other countries soil salinization, deforestation and forest fires are very common and can modify the land use of local communities (Afrasinei et al., 2015, 2017) .

In Figure 4 the flow chart of the steps of the maps production is shown. The activity of data collection using the app as tool for the input of the ground truth is based on the observation of the classified land cover map on the mobile screen. Two main users are expected to collect information: expert users and non-expert users. The expert users will input data for the validation of the first classified map and the production of the final land cover map. Moreover, they will contribute to the collection of land and water uses data. Non-expert users will be involved to collect information on the fluoride contamination of springs, rivers and wells. They will input data about water use of their community and local information of land use.

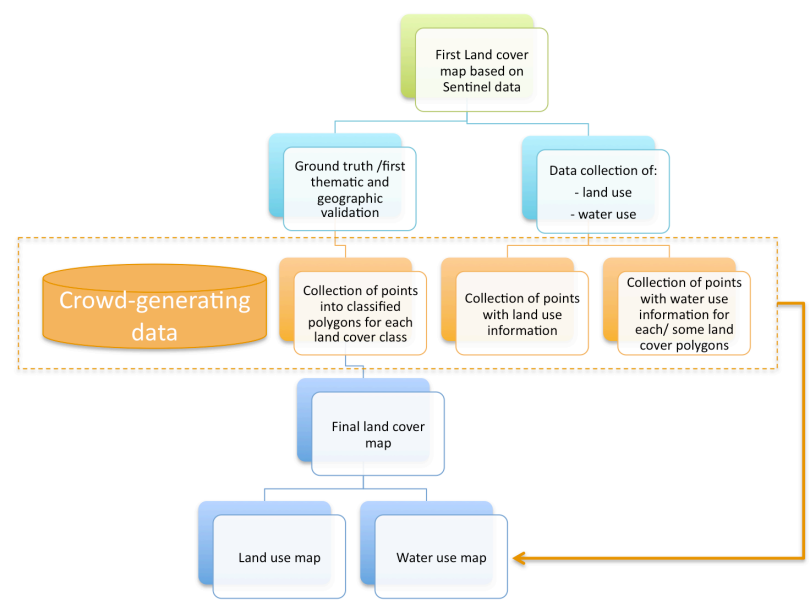

Figure 4. Crowd-generating data activity and map production

\section{FIRST RESULTS}

\subsection{FLOWERED-GeoDBapp}

FLOWERED-GeoDBapp is dedicated to the collection of local geo-information on land use, water uses, irrigation systems, household features, use of drinking water and the other information needful for the specific knowledge of water supply (and then, the most suitable water remediation technique) involving local communities through participative approach.

These data will be used to enhance and strength the information on land cover extracted from satellite data and field activities mapping.

The app is developed with Ionic Framework (https://ionicframework.com), an open source SDK based on Angular that enables developers to build performant, highquality mobile apps using web technologies.

The app can run on both Android and iOS devices and is capable of working in online and offline mode.

To work in offline mode, land cover maps must be downloaded to the device, by first selecting the survey area.

The collected data are stored into a local SQLite database and can be uploaded to the server when a connection is available, after authenticating to the system.

Data collected through the app are stored in a centralized database.

In the Table 1 are summarized the main features of the app.

The Backoffice web application is responsible for storing, viewing and validating data. Administrators can validate data by 
hand or through automated procedures. Finally validated data contribute to generate a land use map.

\begin{tabular}{|l|l|}
\hline Authentication & $\begin{array}{l}\text { - user registration } \\
\text { - login } \\
\text { - Facebook social login } \\
\text { - guest mode access (without } \\
\text { authentication, in offline mode) }\end{array}$ \\
\hline $\begin{array}{l}\text { Maps download } \\
\text { for use in offline } \\
\text { mode }\end{array}$ & $\begin{array}{l}\text { - select an extent on a map } \\
\text { - download tiles on device }\end{array}$ \\
\hline $\begin{array}{l}\text { Data collection } \\
\text { (online/offline) }\end{array}$ & $\begin{array}{l}\text { - localization (GPS, network) on a } \\
\text { land cover map } \\
\text { - data collection through } \\
\text { structured forms } \\
\text { - pictures attachment }\end{array}$ \\
\hline Data browsing & $\begin{array}{l}\text { - browse data in a list } \\
\text { - browse data in a map (markers) }\end{array}$ \\
\hline Social integration & $\begin{array}{l}\text { Share and public data in social } \\
\text { networks }\end{array}$ \\
\hline $\begin{array}{l}\text { Data } \\
\text { synchronization }\end{array}$ & $\begin{array}{l}\text { Send updated data to the server } \\
\text { when a connection is available }\end{array}$ \\
\hline
\end{tabular}

Table 1. App main features

The main features of the backoffice web application are described in Table 2.

\begin{tabular}{|l|l|}
\hline Authentication & - admin login \\
\hline Querying data & $\begin{array}{l}\text { - search collected data by } \\
\text { parameters } \\
\text { - viewing results in a map } \\
\text { - viewing results in a table }\end{array}$ \\
\hline Validating data & $\begin{array}{l}\text { Validate data through batch } \\
\text { algorithms or by hand }\end{array}$ \\
\hline API & $\begin{array}{l}\text { RESTful API that allows } \\
\text { communication between the app } \\
\text { and the backend }\end{array}$ \\
\hline
\end{tabular}

Table 2. Backoffice web application main features

\subsection{Land cover, land use and water use legends}

Figure 5 shows preliminary results of the automatic classification procedure described in 3.1 and applied to the area of Arusha. The land cover map has been extracted by a multitemporal series of only 4 Sentinel-2 images (due to the high cloud percentage in the other available images) while Sentinel-1 integration is still under testing.

This land cover map is a full resolution (10 meters) raster map of the main land cover classes (Artificial, Tree covered vegetation area, No-tree covered vegetation area, Bare soil, Water bodies) obtained by applying a 3 pixel minimum mapping unit. Further developments are in place in order to best fit the map specifications to the project's requirements.

\subsection{Data Collection}

The first release of the app is ready and the first testing activities started.

The collection of the crowd generating data have been organized in four main sections as follow (Figures 6 and 7):

1 - General main section - GPS point collection

2 - Land cover ground truth data collection

3 - Land cover validation data collection
4 - Water use data collection



Figure 5. Land cover classification in the Tanzanian area



Figure 6. Main sections of the data collecting

The first section is the logical core of the dataset collected with the FLOWERED GeoDBapp: in this section a generic user can fix his position in the field and provide some general information regarding the surrounding environment, with the opportunity to report for example the fluoride presence in the area and to collect a picture.

Related to the first mandatory section (geographic position is the key feature of the database), sections two and three hare dedicated to record Land Cover ground truth data and land Cover Validation data. The goal of the section number two is to collect information related to the landscape characteristics with a set of information not obtainable from satellite directly as for example the land cover class coverage percent or a land use class. In a similar way section three is dedicated to the validation of the land cover map. Both sections number two and number three has reserved to specialist users. Contrarily the section number four is open to generic users in order to collect more information about water supply, handling and consumption. 


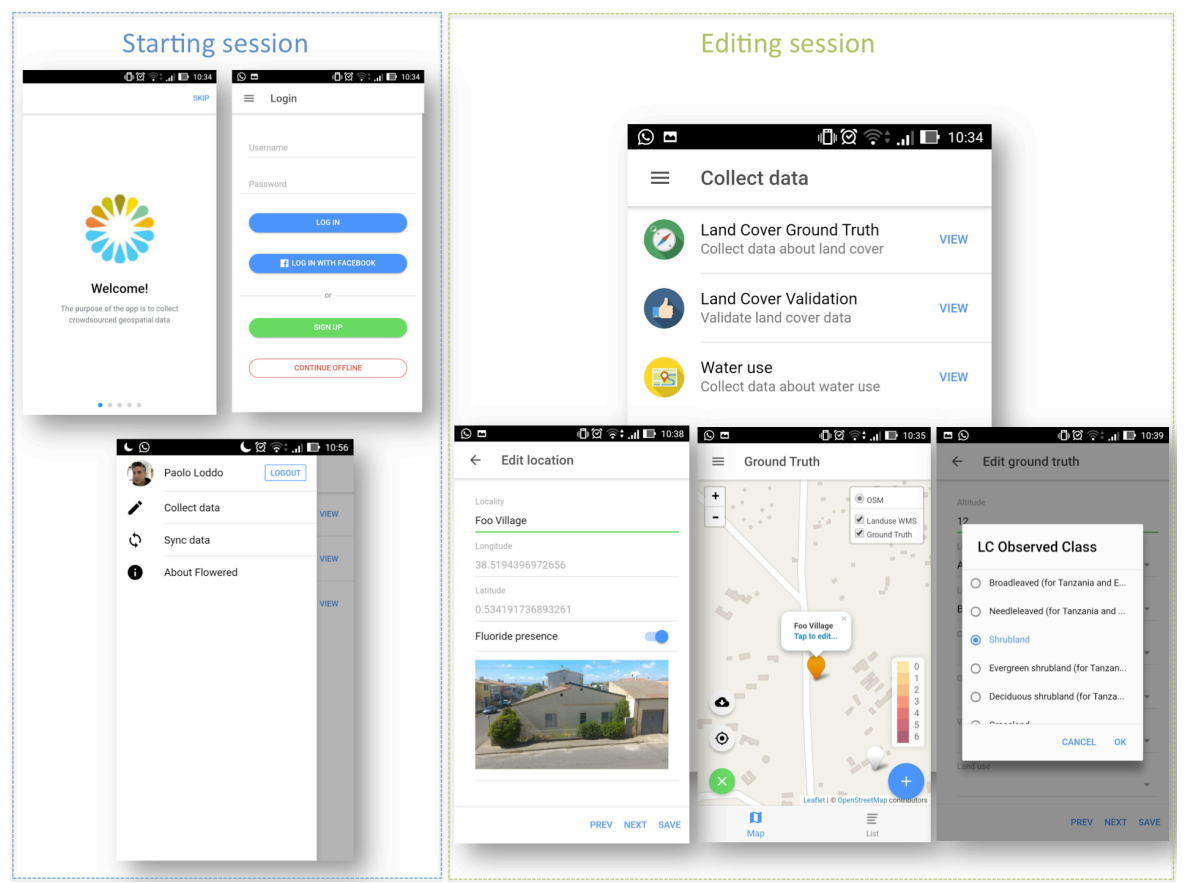

Figure 7. FLOWERED GeoDBapp morkups

\section{CONCLUSIONS}

This study is dedicated to the activity of geo-data acquisition for the implementation of a new system of land-use mapping based not only to a standard legend but capable to give deep information directly from the local communities. For each area of interest in Ethiopia, Kenya and Tanzania, on the basis of the land cover classification created, the information on land use and water use will be collected in the field with the direct engagement of the local communities using the application FLOWERED-GeoDBapp. Furthermore, these data will be used to enhance and strength the information on land cover extracted from satellite data and validate them.

Three main goals will be achieved:

- The transition from the land cover to land use map and the creation of a dynamic database

- The social dimension of the process developed trough a technological transfer to induce regional scientists and administrators to view science as a social, not simply technical, activity.

- The community awareness of the importance of a deep knowledge of land use and interaction with environmental issues for water management.

Moreover, an improved land use legend system will be proposed based on local features and mainly focused on water management in rural areas.

All data collected with the FLOWERED project will be available for the scientific community through a specific and dedicated web portal based on SHARE-GeoNetwork well proven architecture (Melis et al. 2013; Melis et al. 2014; Mattavelli et al. 2016) with a sharing of knowledge based on open data philosophy (Figure 8).

\section{ACKNOWLEDGEMENTS}

This project FLOWERED has received funding from the European Union's Horizon 2020 research and innovation programme under grant agreement N. 690378.

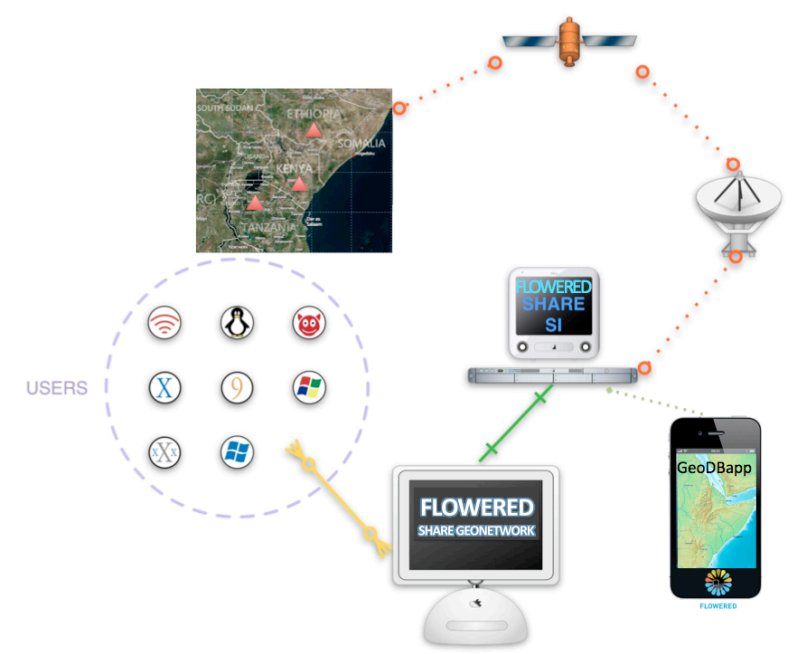

Figure 8. Data collection and sharing into FLOWERED Project

\section{REFERENCES}

Afrasinei G.M., Melis M.T., Buttau C, Bradd Jm, Arras C, Ghiglieri G., 2015. Diachronic analysis of salt-affected areas using remote sensing techniques: the case study of Biskra area, Algeria. In: Proc. SPIE 9644, Earth Resources and Environmental Remote Sensing/GIS Applications VI, 96441D (October 20, 2015); doi:10.1117/12.2194998.

Afrasinei G.M. , Melis M.T., Buttau C., Arras C., A. Zerrim, Guied M., Ouessar M, Essifi B., Mongi Ben Zaied, Amor Jlali, Hanen Jarray, Ghiglieri G., 2017. Classification Methods for Detecting and Evaluating Changes in Desertification-Related Features in Arid and Semi-arid Environments. In Water and Land Security in Drylands Response to Climate Change. Editors: Mohamed Ouessar, Donald Gabriels, Atsushi Tsunekawa, Steven Evett. Springer. ISBN: 978-3-319-54020-7 (Print) 978-3-319-54021-4 (Online). DOI: 10.1007/978-3-31954021-4_23 
Arsanjani, J., Barron, C., Bakillah, M., and Helbich, M. (2013) Assessing the Quality of OpenStreetMap Contributors together with their Contributions. Proceedings of the 16th AGILE conference, Springer, Leuven.

Basiri, A. Jackson, M.,Amirian, P., Pourabdollah, A., Sester, M., Winstanley, A. \& Zhang, L. et 1., 20216. Quality assessment of Open StreetMap data using trajectory mining. Geo-spatial (Taylor \& Francis). Information science, 19(1), 56-68.

Da Pelo S., Melis M.T., Dessì F., Pistis M., Funedda A., Oggiano G.,Carletti A., Soler Gil A., Barbieri M., Daniele Pittalis D., and Ghiglieri G., 2017. An interdisciplinary approach for groundwater management in area contaminated by fluoride in East African Rift System. Geophysical Research Abstracts Vol. 19, EGU2017-8104-2, 2017.

Fawell, J., Bailey, K., Chilton, J., Dahi, E., Fewtrell, L., Magara, Y., 2006. Fluoride in Drinking Water, World Health Organization, London, UK.

Fitzjohn M. (2007). Viewing places: GIS applications for examining the perception of space in the mountains of Sicily. World Archaeology 39, 36-50

Gaciri, S.J., Davies, T.C., (1993). The occurrence and geochemistry of fluoride in some natural waters of Kenya. Journal of Hydrology 143, 395-412

Ghiglieri G. , Da Pelo S., Pistis M 1, Melis M.T., Dessì F., Oggiano G, Abebe B., Tilahun Azazegn T., Haile T., 2017. Geological and hydrogeological features controlling mechanisms of fluoride enrichment in groundwater in the East African Rift System. Flowpath 2017, Cagliari, 14-16 giugno 2017, in press

Ghiglieri G., Balia R., Oggiano G. Pittalis D. (2010) Prospecting for safe (low fluoride) groundwater in the Eastern African Rift: the Arumeru District (Northern Tanzania) Hydrology and Earth System Sciences (HESS) ISSN 10275606) Hydrol. Earth Syst. Sci., 14, 1081-1091.

Ghiglieri G., Pittalis D., Cerri G., And Oggiano G. (2012) Hydrogeology and hydrogeochemistry of an alkaline volcanic area: the NE Mt. Meru slope (East African Rift - Northern Tanzania). Hydrol. Earth Syst. Sci., 16, 529-541.

Gizaw, B. (1996). The origin of high bicarbonate and fluoride concentrations in waters of the main Ethiopian Rift Valley. J. Afr Earth Sci 22, 391-402.

Goodchild, M.F., 2007. Citizens as sensors: the world of volunteered geography. GeoJournal, 69 (4), 211221.

Goodchild, M. F. and Glennon, J. A., 2010. Crowdsourcing geographic information for disaster response: a research frontier', International Journal of Digital Earth, 3: 3, 231 - 241, First published on: 20 August 2010 (iFirst)

Howe, J., 2008. Crowdsourcing: why the power of the crowd is driving the future of business. New York: McGraw-Hill.

Mohapatra, M., Anand, S., Mishra, B.K., Giles, D.E., Singh, P. (2009). Review of fluoride removal from drinking water. Journal of Environmental Management 91, 67-77.
Melis M. T., Dessì F., Locci F., Bonasoni P., Vuillermoz E., 2013. Share Geonetwork: a web-service platform for environmental data sharing. Proc. SPIE 8795, First International Conference on Remote Sensing and Geoinformation of the Environment (RSCy2013), 87951V (August 5, 2013); doi:10.1117/12.2027602.

Melis M.T., Locci F., Dessì F., Frigerio I., Strigaro D., De Amicis M., Vuillermoz E., 2014. NextData Project: development of a web system for climate and paleoclimate data sharing. Rendiconti Online della Società Geologica Italiana, Vol. 31., doi: 10.3301/ROL.2014.140

Mattavelli M., Strigaro D., Frigerio I., Locci F., Melis M.T., De Amicis M., 2016. The IDB: an ice core geodatabase for paleoclimatic and glaciological analyses. Geografia Fisica e Dinamica Quaternaria 39 (1), 59-68, doi: 10.4461/ GFDQ. 2016.39.6

Senaratne $\mathrm{H}$, et al. A review of volunteered geographic information quality assessment methods. Int J Geogr Inf Sci. 2017;31(1):139-67.

Silvertown J. A new dawn for citizen science. Trends Ecol Evol. 2009; 9(24):467-71.

Smedley, P.L., Nkotagu, H., Pelig-Ba, K., MacDonald, A.M., Tyler-Whittle, R., Whitehead, E.J., Kinniburgh, D.G., 2002. Fluoride in groundwater from high-fluoride areas of Ghana and Tanzania. British Geological Survey, Nottingham.

Vogiatzakis I.N. and Melis M.T., 2015. Changing perceptions in Mediterranean Geography: the role of geospatial tools. In Terkenli $\mathrm{T}$ and Cassar L.F. Contemporary Mediterranean Geographies. Cambridge Scholars Publishing.ISBN (10): 14438-7246-6. ISBN (13): 978-1-4438-7246-1

Walvekar, S.V., Qureshi, B.A. (1982) Endemic fluorosis and partial defluoridation of water supplies - A public health concern in Kenya. Community Dent Oral Epidemiol, 10, 3,156160.

Wambu, E.W., Muthakia, G.K. (2011) High fluoride water in the Gilgil area of Nakuru country, Kenya. Research report Fluoride 44, 1, 37-41.

WHO (2011). Guidelines for Drinking-water Quality, fourth ed. WHO Press, World Health Organization: Geneva, Switzerland 